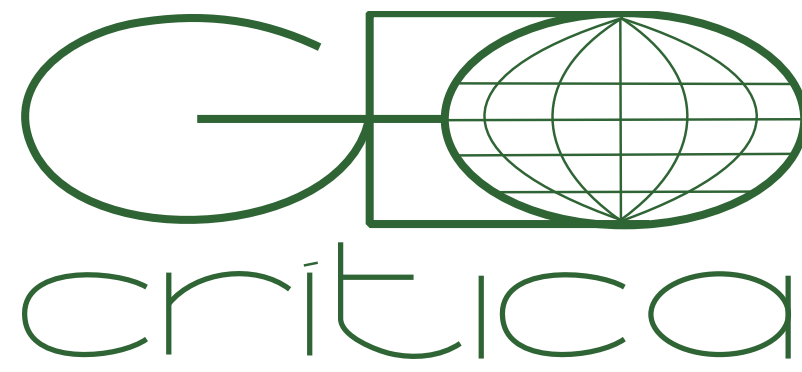

\section{Scripta Nova}

Revista Electrónica de Geografía y Ciencias Sociales Universitat de Barcelona

ISSN: $1138-9788$

Vol. 25, Núm. 2 (2021), p. 131-153

\title{
SOCIOGÉNESIS DEL POLÍGONO DE JINÁMAR (1967-1987). LA PRODUCCIÓN PARALELA DE ESPACIOS DE EXCLUSIÓN Y ESPACIOS TURÍSTICOS EN UN CONTEXTO ATLÁNTICO INSULAR (GRAN CANARIA)
}

\author{
Federico E. González-Ramírez \\ Universidad de Las Palmas de Gran Canaria \\ federico.gonzalez@ulpgc.es
}

Recibido: 30 septiembre 2020; Devuelto para correcciones: 01 marzo 2021; Aceptado: 20 mayo 2021

Sociogénesis del polígono de Jinámar (1967-1987). La producción paralela de espacios de exclusión y espacios turísticos en un contexto atlántico insular (Gran Canaria) (Resumen)

El Polígono de Jinámar es el epílogo de las planificaciones públicas para la vivienda social en Gran Canaria (Canarias), entre el último franquismo en que se adquiere el suelo (1967) hasta su primer poblamiento (1980), ya en democracia. El objetivo de este artículo es mostrar la producción planificada de una categoría de desigualdad, derivada del urbanismo, en un contexto atlántico insular, mediante un proceso de segregación de clase obrera, sin vinculación orgánica con las ciudades precedentes, por la complicidad institucional con la élite propietaria, en un contexto de búsqueda de financiación para la producción paralela del espacio turístico de Maspalomas Costa Canaria. Esta investigación muestra cómo la condición de sus vecinos como primeros expulsados aislados de la ciudad insular supone su deslizamiento hacia una polipatología carencial, derivada del abandono institucional planificado, en un proceso de guetización que permite vincularlo con la violencia estructural masiva de los espacios globales de exclusión.

Palabras clave: Segregación urbana; derecho a la ciudad; espacios turísticos; sociología urbana; ciudades insulares.

\section{Sociogenesis of Polígono de Jinámar (1967-1987). The parallel production of exclusion} spaces and touristic spaces in an atlantic island context (Gran Canaria) (Abstract) The Polígono de Jinámar is the epilogue of the public planning of social housing in Gran Canaria (Canary Islands), starting in the late Francoism, when the land was purchased (1967) and ending with its first population settlement (1980), in democracy times. The present article aims to show the planned production of an inequality category, resulted from urbanism, in an Atlantic island context, by means of a process of segregation of the working class, with no organic connexion to their towns of origin, with the institutional complicity of the owners elite, in a context of seeking financing for the parallel production of the touristic space in Maspalomas Costa Canaria. The present research reveals how the condition of the neighbours as first expelled citizens isolated from the island city entails their sliding towards a deficiency polypathology, resulting from the planned institutional abandonment, in a process of ghettoization, which allows associating it with the massive structural violence of the global exclusion spaces.

Keywords: Urban segregation; right to the city; touristic spaces; urban sociology, island cities. 
en situación de carencia habitacional, a partir de febrero de 1980, fue el último de los grandes polígonos de viviendas promovido por el Instituto Nacional de Urbanización (INUR) en la isla de Gran Canaria, al amparo de la Ley de Actuaciones Urbanísticas Urgentes (ACTUR) de 27 de junio de 1970.

El decreto-ley que dio lugar a ese programa ACTUR, que amparó la producción de este polígono residencial eludiendo el Plan General de Ordenación Urbana de Las Palmas de Gran Canaria, de 1962, permitía delimitar, expropiar y urbanizar grandes zonas, siempre con el objetivo de lograr asentamientos autosuficientes, nuevas ciudades al margen del planeamiento municipal, con aparentes soluciones autónomas en lo residencial y lo económico.

El Polígono de Jinámar se convertía así en el epílogo de la construcción de polígonos residenciales en la isla de Gran Canaria, con los precedentes principales de los polígonos de Arinaga (Agüimes), Las Remudas (Telde), San Cristóbal (Las Palmas de Gran Canaria) y Cruz de Piedra (Las Palmas de Gran Canaria), todas en Gran Canaria, en la promoción de una segregación, programada, de familias de clase obrera, en la década de los años 60 y 70 del siglo XX.

Esa promoción de vivienda pública programada se desarrollaba en un contexto demográfico significativo. Gran Canaria duplicaba el incremento poblacional del conjunto del Estado, por la desruralización de la isla debido a la disminución de acuíferos, la migración interinsular, la pujanza portuaria y de la nueva industria turística, y la descolonización del Sáhara. Un incremento desequilibrado que provocaba una macrocefalia poblacional: el 55\% de la población insular residía, en 1975, en el término municipal de la capital de la isla y la provincia. Las Palmas de Gran Canaria duplicó su número de habitantes en dos décadas, de 193.862 (1960) a 366.454 (1981) (Burriel de Orueta 1982).

El crecimiento de Las Palmas de Gran Canaria estuvo siempre vinculado a mudanzas obligadas de sus habitantes de menores recursos económicos: la expulsión (1800-1860) hacia los Riscos, la colonización (1860-1910) del espacio hasta el Puerto de la Luz, operaciones de expulsión programada provocadas por la intervención estatal (1940-1960) y las últimas fases de nuevas expulsiones programadas, procesos de parcelación incontrolada e impulso de los mencionados polígonos (1960-1975) (Casariego 1987). El denominador común era el crecimiento orgánico, donde se vinculaba la solución habitacional a la relación con la ciudad existente, ya fuera mediante generación doméstica y familiar de asentamientos informales, o bien por la expulsión programada de las familias con menores ingresos desde la centralidad urbana a la periferia mediante planificación pública.

En el caso de Telde, el municipio donde se asentará la mayor parte del nuevo polígono residencial, contará con Plan General de Ordenación Urbana solo a partir de su aprobación en 1985. El municipio tenía más de 60 núcleos de población alrededor de la ciudad central.

La producción del Polígono de Jinámar, entre las ciudades de Telde y Las Palmas de Gran Canaria, supuso la ruptura de esa estrategia tradicional de crecimiento por búsqueda habitacional, sea doméstica o pública, en los municipios entre los que se va a encontrar situado, y por tanto una cesura respecto del crecimiento urbano en el ámbito insular. Por primera vez, la nueva vivienda no iba a estar vinculada, de una u otra forma, a la ciudad. 
Esa producción de espacio segregado para la clase obrera sin vinculación orgánica con la ciudad se desarrolla de forma paralela a la producción del espacio turístico de Maspalomas Costa Canaria, en el Sur de Gran Canaria. La propiedad del suelo de ambos espacios coincide: el Condado de la Vega Grande, según se explica en la tesis doctoral de procedencia de este artículo. La compra de suelo para la segregación de clase obrera se realiza, tras una primera negativa estatal, en el contexto de búsqueda de financiación por parte de esa élite propietaria, en un periodo de dictadura franquista, para el desarrollo de su proyecto turístico (GonzálezRamírez 2015).

Figura 1. Ubicación del Polígono de Jinámar, y de Maspalomas Costa Canaria, en la isla de Gran Canaria (Canarias).

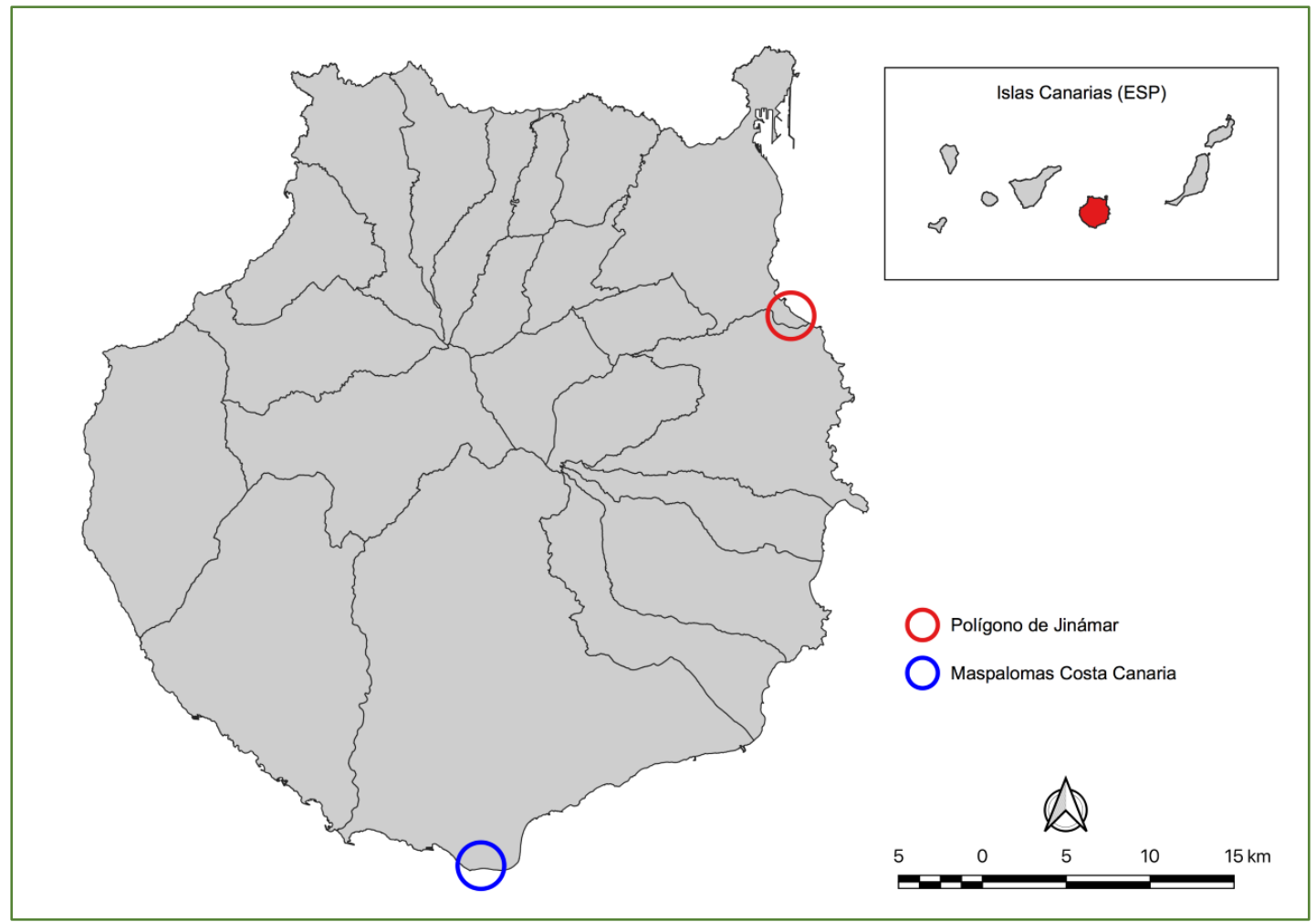

Autor: Jordi Boldú

Este artículo se estructura a partir de la definición de la sociogénesis de una desigualdad específica, la descripción del proceso de producción paralela de ambos espacios, el segregado y el turístico, y del deslizamiento desde la segregación a la exclusión de las familias, para procurar una explicación por la que, entendemos, el Polígono de Jinámar constituye un proceso único y original de producción de un hábitat específico, sin contigüidad con la ciudad, un hecho urbano excepcional, un espacio que es urbano, pero no ciudad. Y sus vecinos, los actores del primer proceso de aislamiento programado insular, los primeros expulsados aislados de la ciudad. 


\section{Sociogénesis de una desigualdad. Apuntes teóricos}

El análisis que pretendemos sobre el origen de una categoría de desigualdad propiciada por el urbanismo, la de los vecinos del Polígono de Jinámar, en un contexto atlántico insular, participa de una reflexión dinámica entre sociología e historia, para comprender la sociogénesis de ese proceso social y los mecanismos de deslizamiento de ese grupo humano hacia una polipatología carencial, adscritos al modelo relacional y a un entramado conceptual del que participan la desigualdad persistente de Tilly, el derecho a la ciudad de Lefebvre, los mecanismos ocultos de la desigualdad urbana de Harvey, y las características de la violencia estructural masiva de los espacios urbanos de exclusión, específicamente el gueto afroamericano, de Wacquant.

\section{El modelo relacional y la persistencia de la desigualdad: explotación de recursos y acaparamiento de oportunidades}

El modelo relacional de la vida social centra su análisis no en "esencias sino vínculos", en una perspectiva comprensiva de la desigualdad y en enfrentamiento frontal con los individualistas metodológicos que procuran explicar la desigualdad social a través de "mecanismos causales (que) consisten en sucesos mentales: las decisiones" (Tilly [1998] 2000, 31-33).

En virtud de esa estrategia relacional, desarrollamos nuestro análisis del Polígono de Jinámar: la producción de una nueva categoría de desigualdad, la de sus habitantes, conducidos desde la condición de grupo humano de clase obrera con carencias habitacionales a la de grupo humano en situación espacial, económica, social y educativa de exclusión, a través de acciones institucionales - la producción del espacio urbano y su abandono - que fracturan la interacción social de ese grupo humano respecto del resto de la sociedad - quiebra respecto a su contigüidad con la ciudad, quiebra respecto de su derecho a la ciudad, quiebra respecto de su derecho a una educación efectiva -, todo ello mediante una producción pública de desigualdad.

El proceso y los vínculos en la interacción social, el cómo y por qué se produjo ese proceso, es el núcleo de nuestro análisis, que soportamos en dos conceptos más sobre el que se establecen los sistemas de desigualdad categorial universales, propuestos por Tilly. De un lado, la explotación, entendida como la disposición de recursos y la exclusión del acceso al valor agregado de la misma, y por otro el acaparamiento de oportunidades, el monopolio sobre un recurso valioso por parte de una red categorial.

El concepto de explotación, aplicado al proceso por el cual se produce la distribución y uso de uno de los principales recursos de la isla de Gran Canaria, el suelo, en un espacio específico para la nueva industria turística, que aparta a la clase obrera del sector económico emergente, en un proceso paralelo a la segregación espacial de esa clase obrera. El acaparamiento de oportunidades, por su parte, en el proceso por el cual la población infantojuvenil del Polígono de Jinámar se ve despojada de su derecho a una educación pública eficiente en lo que supone, entendemos, un proceso de desproveimiento de oportunidades respecto de ese recurso público. 
La adopción de esta perspectiva relacional, y la búsqueda de la persistencia e incremento de la desigualdad en la fractura de la interacción social, se enfrenta a las teorías en las que se imputa al individuo - al vecino del nuevo polígono, en este caso - como preferidor racional y responsable de su polipatología carencial y, en el caso de sus menores, de su logro educativo, un enfrentamiento para el cual ya hemos sido advertidos dado que "los científicos sociales que se ocupan de tales formas persistentes de la desigualdad deben abrirse paso a través de una densa excrecencia ideológica para llegar a las raíces estructurales" (Tilly 2000, 29).

\section{El derecho a la ciudad: producción, espacio social y apropiación. La crítica de la utopía corbusiana}

La adopción de ese análisis relacional y no determinista, y la focalización en la fractura en la interacción social del grupo humano objeto de nuestro estudio, se encuentra íntimamente relacionada con otros pilares conceptuales: el derecho a la centralidad, la producción del espacio (social), y la apropiación (Lefebvre [1968] 1975, [1974] 2013) - sobre los que sustentamos nuestra interpretación última del Polígono de Jinámar como epílogo grotesco en el ámbito del Archipiélago - de la propuesta utópica corbusiana de la solución vertical, ineficaz para la clase obrera (Hall [1988] 1996).

Ese epílogo insular de producción planificada de vivienda social supone la cristalización última de una amplia expresión occidental en un sistema de relaciones económicas concreto. Lefebvre da cuenta de la frustración del relato utópico: la segregación urbana "considerada como proyección sobre el terreno de la división social del trabajo, muestra la imposibilidad de crear una sociedad integrada por vías del urbanismo". La segregación, consecuencia de un sistema económico y su división social del trabajo, adopta perfiles utópicos, de asistencia social, porque "en un país democrático, los poderes públicos no pueden decretar públicamente la segregación como tal. Por ello, con frecuencia adoptan una ideología humanística que se torna en utopía en el sentido más anticuado, cuando no en demagogia". La conclusión se sitúa en el ámbito de la paradoja, en cuanto que "esta sociedad practica la segregación. Esa misma racionalidad que se pretende global (organizadora, planificadora, unitaria y unificante) [...] proyecta sobre el terreno la separación”. “Con qué resultados? Sin ninguna duda, fenómenos paradójicos de integración desintegrante que atentan en particular a la realidad urbana" (Lefebvre 1975, 114-21).

La definición del derecho a la ciudad por Lefebvre era contemporánea del inicio de los trámites burocráticos que conducirían a la existencia del Polígono de Jinámar. La segregación urbana practicada supondría la vulneración de ese derecho.

"El derecho a la ciudad se manifiesta como forma superior de los derechos: el derecho a la libertad, a la individualización en la socialización, al habitat y al habitar. El derecho a la obra (a la actividad participante) y el derecho a la apropiación (muy diferente del derecho a la propiedad) están imbricados en el derecho a la ciudad" (Lefebvre 1975, 159). 
Esa definición de Lefebvre nos aporta dos conceptos fundamentales a partir de los cuales hemos abordado y pretendido entender los procesos sociales generados en el Polígono de Jinámar en el periodo establecido. El análisis que proponemos sigue la línea teórica trazada en el que el "derecho a la ciudad es derecho a la centralidad, a no convertirse en periferia", un derecho cuya base "no es contractual ni natural, sino que está relacionada con un carácter esencial del espacio urbano: la centralidad" (Bettin 1982, 134). La supresión del derecho a la centralidad supondrá por tanto la supresión del derecho a la ciudadanía y provocará la deserción de la búsqueda y ejercicio de ese derecho en la institución establecida para su primer desarrollo: el ámbito educativo.

A la crítica de la propuesta utópica, de la segregación, de la supresión del derecho a la ciudad y la centralidad, unimos la adopción del concepto de espacio como producción, como "relacion social inherente a las relaciones de propiedad [...]" (Lefebvre 2013, 141) y consecuencia de unas relaciones económicas y políticas dadas.

El espacio así producido por unas relaciones de propiedad y las instituciones estatales, se convierte en espacio social, que "implica, contiene y disimula las relaciones sociales, a pesar de que, como hemos dicho, ese espacio no es una cosa, son un conjunto de relaciones entre las cosas", y fundamentalmente de relaciones económicas, de ahí que la segregación obrera del Polígono de Jinámar, su apartamiento de la ciudad, cristalice en una consecuente segregación respecto de la actividad económica, dado que el espacio urbano producido conlleva - "el espacio social se produce y reproduce en contacto con las fuerzas productivas" (y las relaciones de producción)" - un espacio social inherente e igualmente producido (Lefebvre 2013, 133-39).

El derecho a la ciudad, a la centralidad, supone también el derecho inherente a la apropiación, y permite identificar el proceso de los vecinos del Polígono de Jinámar que, desprovistos de ciudad, y con un espacio social de segregación producido por el Estado en virtud de las relaciones de propiedad existentes en ese momento en Gran Canaria, se procuran un espacio social propio en la exigencia de transformación del espacio urbano que les ha sido asignado. Procuran esa conversión a la condición de "espacios apropiados: no soportados, no aceptados por una resignación pasiva” (Lefebvre 1975, 136) para su propio entorno urbano, ejerciendo desde la ciudadanía - aunque les privaran de ciudad - el ejercicio crítico por el cual "el grupo se apropia de un espacio natural modificado para servir a sus necesidades y posibilidades” (Lefebvre 2013, 213).

La tensión entre los conceptos de producción y construcción, contenidos en la descripción del derecho a la ciudad de Lefebvre, está presente en nuestro análisis. El concepto de construcción, de "obra" y "actividad participante" descritos, lo consideramos en nuestra propuesta en relación con la pugna por la apropiación que establecen los vecinos del Polígono de Jinámar. A un espacio social producido los vecinos trataron de oponer un espacio social construido, mediante su apropiación.

Su trazo teórico aporta, además, una perspectiva adicional, respecto de los territorios - como el sur francés, al que se refiere, en los mismos años de la producción de nuestro objeto de estudio - turísticos y a la vez militares, espacios que "están producidos [...] son productos políticos, espacios estratégicos" (Lefebvre 2013, 140), sobre los que se sustentará el giro 
económico de Gran Canaria hacia la industria turística en un proceso paralelo, como apuntamos, a la segregación espacial de la clase obrera.

\section{La interacción entre espacio y procesos sociales: las paradojas de la desigualdad, la incubación de la guetización, la violencia estructural masiva}

El armazón teórico de Lefebvre tiene su continuidad, en nuestra propuesta, en la vinculación de espacio y procesos sociales, dado que "[...] la comprensión del proceso social en toda su complejidad depende de la forma de enfocar la forma espacial" (Harvey [1973] 2007, 31), como nos demanda el modelo relacional y la búsqueda de los mecanismos causales que gestan categorías en la interacción social. Harvey subraya, precisamente, que "los modernos planificadores reconocen que no cuentan con demasiadas pruebas en las que basar sus ideas acerca del buen diseño de una ciudad", y que "es quizá mucho más razonable considerar la ciudad como un complejo sistema dinámico en el cual las formas espaciales y los procesos sociales se encuentran en continua interacción". La indagación sobre esa dinámica de interacción entre espacio y procesos sociales es la que procuramos acometer, con la advertencia sobre la paradoja de que "[...] en un complejo sistema urbano, los 'mecanismos ocultos' de redistribución del ingreso normalmente aumentan las desigualdades en vez de reducirlas" (Harvey 2007, 40-48).

La redistribución de ingreso que supone para la clase obrera la obtención de una vivienda social puede provocar el incremento de la desigualdad. No será la última advertencia, ni la última paradoja. Es necesario atender "la cadena de eventos y condiciones que han llevado a la exclusión social" dado que la línea de pobreza, establecida en virtud del ingreso económico, subestima "el impacto negativo de la gran inestabilidad social y del aislamiento" (Mingione 1996, 1, citado por Auyero, 2010, 27). La identificación de esa paradoja del incremento de la desigualdad, pese a la redistribución de ingresos que supone una mejor vivienda, y la cadena de eventos que conduce a la exclusión social, más allá del ingreso económico, forman parte sustancial de nuestra investigación.

Los análisis sobre los espacios sociourbanos de exclusión racializados nos aportan más herramientas conceptuales. La necesidad de explorar desde el origen la cadena de eventos que conduce a la exclusión - "el proceso de guetificación negra (con) aumentos abruptos de la desocupación, el delito, los retrasos educativos y otras dislocaciones sociales [...] se remonta a la formación inicial del gueto como una institución de exclusión racial en las primeras décadas del siglo XX" -, y la identificación de algunas de sus características nos permiten evaluar sobre si nuestro objeto de estudio forma parte de esos espacios globales de exclusión. La negligencia pública, que pretende esconderse tras la generación de una supuesta infraclase; el abandono planificado y quiebra selectiva de los servicios públicos; la segregación residencial multiplicadora de carencias; el estigma espacial y su vinculación con el desempleo; entre otros. Unas características de los espacios universales de exclusión cristalizadas en las escuelas de custodia y el abandono de la educación pública, donde las escuelas públicas "quedaron reducidas, en sustancia, a ser establecimiento de custodia y no 
de educación, que sirven más para atrapar a los pobres que para abrir una compuerta de escape del gueto" (Wacquant 2010b, 46-89).

Tres características sintetizan la "violencia estructural masiva" ejercida sobre los habitantes del gueto norteamericano, provocada por "una serie de transformaciones económicas y políticas que se refuerzan mutuamente": el desempleo masivo, "crónico y persistente que, para todo un sector de la clase obrera, se traduce en la desproletarización y la expansión de la precariedad"; la relegación a los barrios desposeídos de esa clase obrera, con menores recursos públicos, con características raciales específicas; y la estigmatización "creciente en la vida cotidiana y en el discurso público" (Wacquant [2006] 2007, 40-41).

La inexistencia de elementos étnicos, raciales, ni de otras características que confluyen en el caso del espacio de exclusión norteamericano de referencia - y que no comparte con otros espacios, como barrios latinos, judíos italianos (Wacquant 2010a, 26-27) - provoca en el caso del Polígono de Jinámar que renunciemos, en todo momento, a su denominación como gueto, calificativo que fue adoptado por las instancias públicas, mediáticas y por el imaginario colectivo para referirse a ese espacio urbano en sus primeros años, y que acudamos en todo momento al concepto de espacio de segregación o exclusión para nuestras referencias. Sí empleamos, como herramienta conceptual, proceso de guetización o incubación de la guetización, para referirnos a la dinámica que se desarrolla y que conduce desde la segregación a la exclusión en sus años fundacionales, por su poderosa connotación expresiva y definidora de ese tránsito.

\section{La reflexión canaria del espacio: las expulsiones que crearon ciudad, la fractura de la contigüidad, la "triple insularidad"}

La comprensión del fenómeno del Polígono de Jinámar precisa además del contexto en el que directamente se produce, el de la isla de Gran Canaria, con una delimitación geográfica inherente, y con un proceso económico, social y político igualmente específicos. Y, también, del enhebramiento cronológico establecido por Casariego (1987) para la conformación de Las Palmas de Gran Canaria - en mudanzas obligadas de expulsiones, expulsiones programadas, intervenciones estatales y parcelaciones no controladas -, y la periodización de Bescós Olaizola (1984) sobre la promoción de vivienda económica en la capital grancanaria, en que intervención estatal y urbanización marginal impulsan su crecimiento.

El análisis de la producción paralela de espacio turístico y espacio de exclusión, concebida desde las relaciones de economía y política en Gran Canaria y su cristalización en la década de los sesenta y los setenta del siglo XX, ha sido posible a partir del trabajo de Nadal (1983) y su descripción del proceso de conformación de la ciudad turística en el Sur de la isla a través de la propiedad del suelo.

El hallazgo del aislamiento del Polígono de Jinámar, por último, ya había sido anunciado, dado que "hoy por hoy, Jinámar sigue siendo un enclave no sólo alejado de los principales núcleos de población, son también segregados de su entorno, afectado por lo que se ha venido en llamar la triple insularidad: la que proporciona su alejamiento y segregación respecto a la Isla y el Archipiélago" (Parreño y Moreno 2006, 187). 


\section{Espacio de segregación obrera y espacio turístico: la producción socioespacial paralela del periodo franquista}

Dos fenómenos espaciales paralelos se produjeron en Gran Canaria a partir de la década de los sesenta del pasado siglo, en plena dictadura franquista. La isla, y su capital, Las Palmas de Gran Canaria, se encontraban en la proximidad de su punto crítico (Lefebvre 1975, 92), la encrucijada provocada por el descenso de la actividad agrícola y la emergencia de una nueva industria turística, las migraciones del campo a la ciudad, la concentración urbana y la gestión de los espacios para esa nueva industria. Los propietarios de esos espacios iniciaron su planificación, con la participación cómplice de las instituciones. Planificación paralela - la de los espacios segregados para la población con menos recursos, y la planificación de los espacios para el turismo -, vinculada a la propiedad del suelo - el Condado de la Vega Grande, en ambos casos -, y la participación de las instituciones del último franquismo.

Figura 2. Ubicación de los polígonos de vivienda de la década de los 70 en Gran Canaria, en Las Palmas de Gran Canaria, Telde y Agüimes.

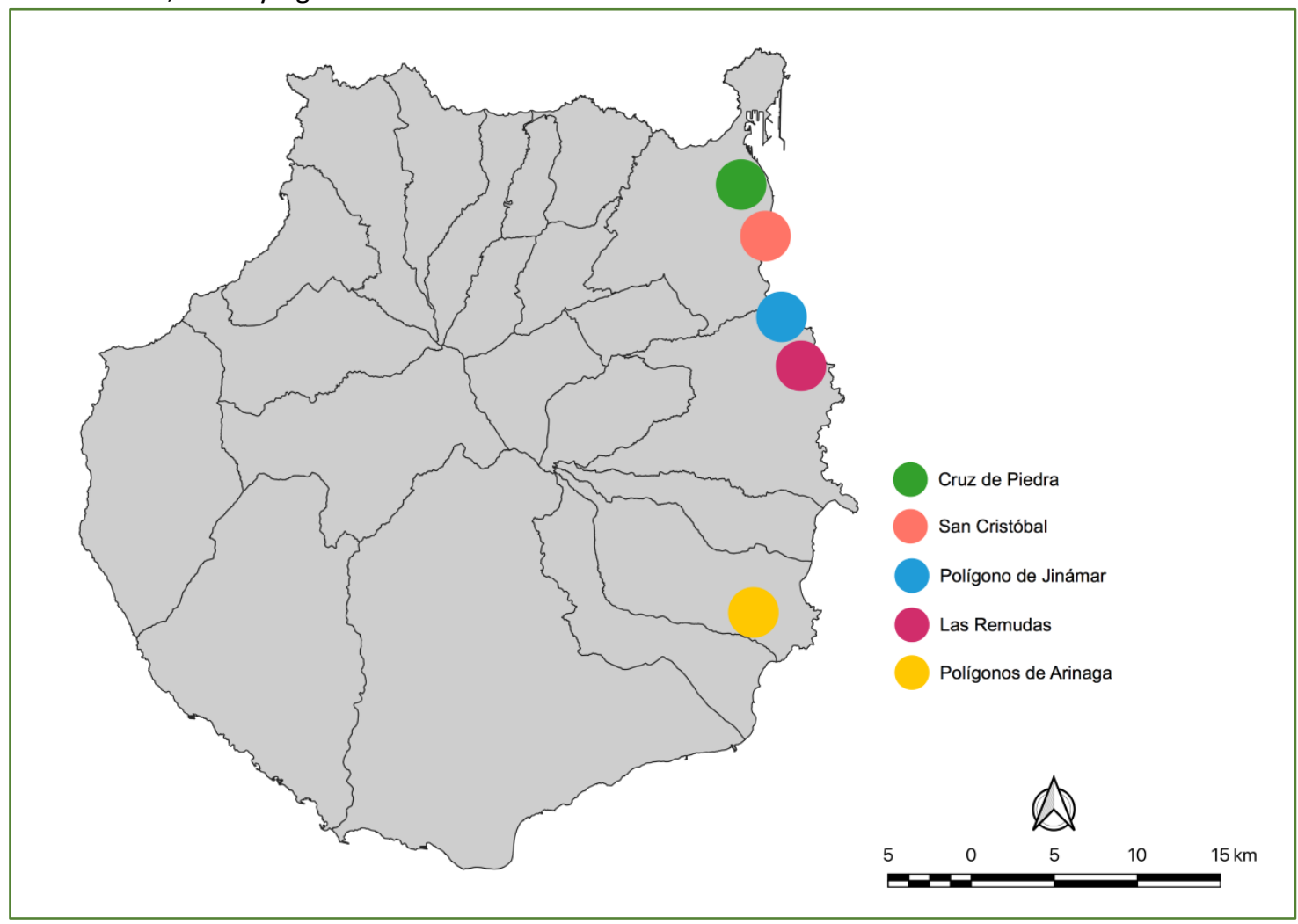

Autor: Jordi Boldú, a partir de Bescós Olaizola (1984)

A finales de los años 60, el Estado acometía su iniciativa más importante, en términos cuantitativos, para la construcción de vivienda social con los proyectos del Polígono de San Cristóbal - 4.766 viviendas previstas -, Polígono de Cruz de Piedra - 1.404 casas previstas , y ya, por último, Polígono de Jinámar - más de 11.600 viviendas previstas -. A esos polígonos se sumaba el de Las Remudas, en Telde, y otro más en Arinaga (Agüimes). Esa iniciativa, que facilitaba vivienda a un amplio sector de la población que se encontraba en situaciones diversas de carencias en la habitabilidad - familias numerosas, ocupación de viviendas de 
familia extensa, pero también cuarterías y chabolistas - produjo espacios de embolsamiento de este sector de la población en zonas funcionalmente dispuestas para ello, en consonancia, esta vez sí, con la tradicional producción de espacios y categorización social reconocida en la propia memoria del Plan General de Ordenación Urbana (PGOU) de la capital grancanaria.

Ese embolsamiento en polígonos de mayores dimensiones que las iniciativas estatales hasta ahora impulsadas - en correspondencia con el desarrollo demográfico - trataba de dar una solución insular a un problema insular. Gran Canaria producía espacios urbanos municipales segregados y vinculados a sus respectivas ciudades para atender problemas sociales: los Polígonos de Cruz de Piedra y de San Cristóbal acogieron a vecinos de Las Palmas de Gran Canaria; el Polígono de Las Remudas, a vecinos de Telde, la capital grancanaria y a un cupo de familias evacuadas del Sáhara; y el Polígono de Arinaga, a familias con las mismas carencias del Sureste de la Isla.

Pero la coincidencia de todas esas iniciativas en el tiempo permite advertir una solución supramunicipal. Máxime cuando buena parte del suelo de ambas planificaciones, la turística de Maspalomas Costa Canaria y la habitacional para la clase obrera del Polígono de Jinámar, era de la misma propiedad. Si "en un país democrático, los poderes públicos no pueden decretar públicamente la segregación como tal [...] por ello con frecuencia adoptan una ideología humanística que se torna en utopía en el sentido más anticuado, cuando no en demagogia" (Lefebvre 1975, 115), la asunción de una voluntad asistencial o humanística de la planificación de los grandes polígonos por parte de la Administración estatal en la España predemocrática se hace todavía más compleja.

La producción de esos espacios, a tenor de la dimensión ya advertida de la influencia económica, demográfica y social de la capital, atendía a una planificación insular paralela: proporcionar vivienda en espacios segregados al excedente de población, y liberar los espacios que ya gestionaban la industria turística - Las Palmas de Gran Canaria -, y los nuevos espacios para esa industria - Maspalomas Costa Canaria -. Gran Canaria recibía a más del $50 \%$ de todos los turistas que llegaban a Canarias, desde 1950 (8.000 visitantes, un $53,33 \%$ ) hasta 1970 (466.500, un 56,82\%). Aunque el porcentaje disminuyó en la década de los 70 (45,07\% en 1975; 40,55\% en 1980), en Gran Canaria y Las Palmas de Gran Canaria se ubican en los primeros años de ese crecimiento turístico, en la década de los sesenta y los setenta, las primeras inversiones y la actividad del sector económico emergente (Hernández Luis 1997-1998). Pero la nueva industria, concentrada en principio en Las Palmas de Gran Canaria, requería de nuevos espacios, que estaban en el Sur de la Isla.

Esa planificación turística estará vinculada en el tiempo y la propiedad del suelo a la producción del Valle de Jinámar como urbanización residencial segregada. En 1962, el Ayuntamiento de Las Palmas de Gran Canaria recibía un proyecto de promoción turística para el mismo Valle de Jinámar. Finalmente no se lleva a cabo, pero cinco años después la Gerencia de Urbanismo propone la expropiación de la finca a sus propietarios en una operación considerada como "un mecanismo que permitió a los propietarios hacer un interesante negocio inmobiliario con fincas que no tenían expectativas de urbanización" y que fueron "apoyadas adecuadamente por las delegaciones territoriales del Ministerio de la 
Vivienda" (Parreño y Moreno 2006, 188), dado que era inviable lograr el beneficio social anunciado como justificación al pago de una expropiación cuantiosa.

\section{La producción del Sur turístico}

El mismo propietario que lograba esa venta, el Condado de la Vega Grande, mediante una operación estatal con el que era probablemente el único comprador posible para una finca de esas dimensiones, una institución pública, planificaba a finales de los años sesenta el Sur de Gran Canaria. El Conde y sus consejeros pretendían urbanizar 500.000 metros cuadrados en Los Llanos del Inglés - situados al este del barranco de Fataga - para lo que calculaban un presupuesto de 20 millones de pesetas: en 1958 y 1959 surgen los primeros proyectos para atraer a un turismo que hasta entonces visitaba Las Palmas de Gran Canaria. Su experiencia en la urbanización se limitaba entonces a tres poblados aparceros, - en San Fernando, Juan Grande y Arguineguín - realizados por el arquitecto Manuel de la Peña. Pero, para urbanizar las 15.000 hectáreas que poseía el mismo propietario, se requería capacidad inversora: primero se negocia con las empresas Entrecanales y Távora y con Wagons Lits-Cook, posteriormente con el Banco Español de Crédito, mientras el propio Cabildo de Gran Canaria - presidido por Matías Vega Guerra - muestra su interés por comprar una parcela junto al palmeral del Oasis para realizar un parador turístico. Finalmente, un concurso internacional, en 1962, y ganado por un proyecto francés - Societé pour l'Etude Technique d'Amagements Planifiés (SETAP) - sienta las bases para la planificación del proyecto Maspalomas Costa Canaria, en una superficie de 2.000 hectáreas. Para llevarla a cabo, se sigue precisando capital inversor. Se llega a un acuerdo previo con el grupo March: de 1.200 millones de pesetas, se concluye en un acuerdo de valoración del terreno - esas 2.000 hectáreas - por 800 millones de pesetas. El grupo March asumirá la mitad de la inversión. Pero el acuerdo se rompe en octubre de 1962 (Nadal 1983, 77-88).

El 15 de octubre, el Conde crea una única sociedad y cambia de estrategia de inversión, y desde 1962 a 1969 inicia una primera fase con la venta de parcelas a pequeños inversores. Se inicia la primera urbanización, San Agustín, como había previsto el proyecto ganador del concurso de ideas, ejecutado por el arquitecto Manuel de la Peña, que inaugura los espacios exclusivos para el ocio turístico en la Isla. En una segunda fase (1969-1972) se prescinde del pequeño comprador y entran inversores alemanes. Es una fase más agresiva, y surgen los apartamentos como herramienta comercial del ocio turístico en la Isla. A partir de 1972 disminuirá la venta de solares.

La parcelación del Sur tendrá implicaciones no sólo económicas, también institucionales. En el Sur de la Isla se crea una Comisión de Desarrollo del Plan Maspalomas Costa Canaria, un órgano asesor para redactar las ordenanzas de los Planes Parciales que se presenten en la zona. Su presidente será el Conde de la Vega Grande, Alejandro del Castillo y del Castillo. Sus vicepresidentes, Alejandro del Castillo y Bravo de Laguna y Pedro del Castillo y Bravo de Laguna. El alcalde de San Bartolomé de Tirajana estará como vocal, al igual que el secretario general del Ayuntamiento. El secretario de esa Comisión será Pablo Elola Albisu, administrador del Conde. En la práctica, la constitución de esa Comisión suponía el control 
por la empresa Maspalomas Costa Canaria, por el Conde de la Vega Grande, de la planificación de todo el Sur turístico, en una situación de jerarquía sobre los representantes municipales.

“[...] cualquier proyecto de construcción, aparte de ser efectuado de acuerdo con las ordenanzas, es presentado a la Comisión de Desarrollo, que emite un informe. Con posterioridad, ésta informa al Ayuntamiento, que a su vez lo pasa al Ministerio de la Vivienda. De suyo, si es aprobado por la comisión, también lo es por la institución municipal, y no solamente por el hecho de que el alcalde y el secretario del Ayuntamiento estén en esa comisión, sino también porque algunos concejales de esa corporación son, a su vez, empleados del promotor de la urbanización" (Nadal 1983, 92).

La constitución de esa Comisión, y la aprobación mecánica por parte del Ministerio de la Vivienda de sus acuerdos, suponía también de facto que la empresa urbanizadora del Conde "según va promoviendo nuevas urbanizaciones, modifica las ordenanzas, para de este modo controlar mejor los proyectos que se ejecutan", y su grado de influencia política se traduce "en los intentos de trasladar la sede del Ayuntamiento de la villa de San Bartolomé a la costa, e incluso, la creación de un nuevo municipio separado del de San Bartolomé" (Nadal 1983, 92).

Esa imbricación entre los intereses particulares e institucionales formará parte permanente de las decisiones de la planificación de la Isla, tanto del Sur de Gran Canaria como del Polígono de Jinámar. Manuel de la Peña ha sido el arquitecto de los primeros poblados para aparceros que promueve esa propiedad, será el arquitecto de la primera fase urbanizadora del Sur de la Isla - San Agustín -, es citado como el arquitecto de Maspalomas Costa Canaria en su conjunto y participa en el jurado del concurso internacional que designa el proyecto francés como ganador, aunque no se llevará a cabo. En ese concurso, se define a Manuel de la Peña como "arquitecto del Instituto Nacional de la Vivienda de Las Palmas y colaborador técnico del Conde de la Vega Grande" (Nadal 1983, 80).

\section{La producción del espacio de segregación}

El Valle de Jinámar, una enorme superficie de suelo rústico perteneciente a una sola finca catastral, propiedad de Alejandro del Castillo y del Castillo y que se encontraba en usufructo por María Teresa Rivero del Castillo-Olivares, cumplía los requisitos para la estrategia de pugna contra la especulación del suelo que se encargó a la Gerencia de Urbanismo: la regulación del mercado del suelo mediante leyes de suelo y ordenación urbana (1956 y 1975), que permitieron la creación de polígonos residenciales al margen del planeamiento municipal en toda España. Pero también cumplía los requisitos - terreno con un solo propietario, terreno para un solo comprador - de propiedades susceptibles para la búsqueda de capital con que proseguir la dinámica de inversión en Maspalomas Costa Canaria, la génesis de la industria turística en la Isla, y la derivación del beneficio desde la agricultura al turismo por parte de la propiedad, y su consecuencia: la planificación paralela - con la activa y necesaria complicidad institucional - de espacios segregados residenciales para la 
población con menos capital económico, cultural y educativo de la Isla, por un lado, y de espacios para la población europea que engendraba la sociedad del ocio de masas, de otro.

En Las Palmas de Gran Canaria, el suelo para cumplir los objetivos de necesidad de vivienda de la Gerencia de Urbanismo, según el informe con que se desestimó en primera instancia comprar la finca del Valle de Jinámar, en 1965, estaba cubierto con la expropiación de 57 hectáreas en la Vega de San José - que se convertirían en el conocido como Polígono de San Cristóbal - y de 20 hectáreas para el Polígono de Cruz de Piedra. Así se atendían los objetivos del III Plan Nacional de la Vivienda (1961-1968). Pero los objetivos, o las decisiones, cambiaron en solo dos años.

Precisamente esa Delegación Provincial de Vivienda a la que estaba adscrito el arquitecto del Conde, Manuel de la Peña, solicita en 1965 que el Ministerio de la Vivienda "procediese a la adquisición de la finca (el Valle de Jinámar) dado el ofrecimiento que hacía su propietario". El Servicio de Programación y Coordinación de la Gerencia de Urbanización decide archivar el 30 de diciembre de 1965 ese informe, debido a que las necesidades de suelo previstas para Las Palmas de Gran Canaria ya estaban cubiertas con los polígonos de Cruz de Piedra y San Cristóbal (Parreño y Moreno 2006, 179).

Pero el 2 de noviembre de 1967, dos años después, varía esa decisión ministerial. Un documento del registro central del Instituto Nacional de la Vivienda ${ }^{1}$, firmado por el director general, comunica que "se ha resuelto encargar a esa Gerencia de Urbanización los proyectos y trabajos correspondientes a las fases de delimitación y expropiación de un polígono residencial de 250 hectáreas en Las Palmas de Gran Canaria" (González-Ramírez 2017).

Esas 250 hectáreas - finalmente serán 307 - son, precisamente, propiedad de Alejandro del Castillo y del Castillo. El Ministerio de la Vivienda la compra finalmente en 1968, unos meses después, por 217.646.150 pesetas. La pretensión de venta de la finca del Valle de Jinámar para viviendas sociales, pese a la negativa del Gobierno inicial y pese a la lejanía de las ciudades existentes, en el contexto de búsqueda de financiación para la producción de Maspalomas Costa Canaria, había sido lograda. El polígono residencial será el Polígono de Jinámar.

El suelo que finalmente se convertiría en Polígono de Jinámar, hasta quince veces superior al comprado para el Polígono de Cruz de Piedra y seis veces más extenso que en el Polígono de San Cristóbal, debió ser objeto de continua negociación, toda vez que el 2 de noviembre de 1967, seis meses antes de la delimitación inicial de los terrenos, el directorgerente de la Gerencia de Urbanismo ya se complacía en comunicar el encargo de los proyectos y trabajos correspondientes a las fases de delimitación y expropiación de ese polígono residencial de 250 has. en Las Palmas de Gran Canaria.

La negativa inicial a comprar se convirtió, por tanto, en el periodo de dos años, en un expediente de expropiación. La superficie de suelo a expropiar aumentaría en cada comunicación oficial. Solo cuatro meses después del encargo de expropiación, el director general del Instituto Nacional de la Vivienda, en uso de las atribuciones que le estaban

1 Archivo Servicio de Arquitectura y Urbanismo del Ayuntamiento de Las Palmas de Gran Canaria. Expediente 62A. Carpeta 56. "Encargo fases delimitación y expropiación polígono residencial de Las Palmas de Gran Canaria". Instituto Nacional de la Vivienda. Ministerio de la Vivienda. 2 de noviembre de 1967. 
conferidas, se complacía en significar al director general de la Gerencia de Urbanismo que había resuelto ampliar dicho polígono hasta un total de 307 hectáreas, es decir, 57 hectáreas más que cuatro meses antes, y le encomienda la totalidad de las fases que restan del susodicho polígono y por primera vez le dará su nombre definitivo: "Se denominará Jinámar"2.

\section{La justificación del Plan Parcial}

El 1 de junio de 1968 se certificaba que la zona que interesaba a la Administración aumentaba y eran finalmente 307 hectáreas (3.074.500 metros cuadrados), según el documento que con esa fecha se eleva al director-gerente de Gerencia de Urbanismo de Delimitación y Previsiones de Planeamiento del Polígono 'Jinámar', en los términos municipales de Las Palmas y Telde (1.409.375 metros cuadrados pertenecen al municipio de Las Palmas, el 45,85\% de la superficie, y 1.665 .125 metros cuadrados al término municipal de Telde, el 54,14\%)33.

En esa delimitación inicial ya se justifica la intervención estatal, sin contar con los ayuntamientos afectados por la medida, en virtud del artículo $3^{\circ}$ de la Ley 52/1962, de 21 de julio, sobre valoración de terrenos sujetos a expropiación en ejecución de los Planes de Vivienda y Urbanismo, dado que se autoriza al Gobierno la delimitación de polígonos de actuación existan o no confeccionados o aprobados los respectivos Planes de Ordenación Urbana Generales o Parciales, la modificación, en su caso, de las previsiones contenidas en Plan General que haya de actuarse mediante la delimitación prevenida en el artículo 121 de la Ley del Suelo y la fijación de precios máximos y mínimos de valoración.

El permiso aludido se circunscribía a zonas o demarcaciones en las que hubiera de actuarse para la ejecución del Plan Nacional de la Vivienda y de los de Urbanismo, y cuando lo exigieran los proyectos urbanos de inmediata ejecución - caso en el que, dice el documento, se encuentra el Polígono de Jinámar - pero, curiosamente, se propone la delimitación, por una parte, por las necesidades del Instituto Nacional de la Vivienda, y por otra por distintas consideraciones de orden técnico y económico-social que afectan a las poblaciones y a los terrenos con posibilidades de utilización urbana en esas localidades, que aconsejan la elección de este polígono. No se explica por qué se diferencian las necesidades del INV y las de la población, ni si son las mismas.

Esas consideraciones contenidas en el documento de junio de 1968 serán la existencia de 7.500 familias en "condiciones ínfimas"; el "crecimiento explosivo" de la población; la idónea ubicación para la absorción de mano de obra desde el Puerto de la Luz y la zona industrial de Telde, así como por el hecho de que "el desarrollo de ambas ciudades se localiza en la dirección de la autopista de Gando, que comunica las dos entradas de la Isla, el aeropuerto y el puerto"; la facilidad de acceso y transporte; el "abastecimiento de agua

2 Archivo Servicio de Arquitectura y Urbanismo del Ayuntamiento de Las Palmas de Gran Canaria. Expediente 62A. Carpeta 56. Madrid. 9 de marzo de 1968. Encargo totalidad fases polígono residencial Jinámar de 310 hectáreas en Las Palmas de Gran Canaria.

3 Archivo Servicio de Arquitectura y Urbanismo de Las Palmas de Gran Canaria. Expediente 62A. Car-peta 56. Madrid. 1 de junio de 1968. Delimitación y Previsiones de Planeamiento del Polígono 'Jinámar', en los términos municipales de Las Palmas y Telde. 
inmediato"; la posibilidad de manufactura de "productos para el mercado africano"; y, finalmente, pese a lo esgrimido por el Ministerio en su primera respuesta al propietario de los terrenos en su propuesta de venta, la carencia de suelo para vivienda social dado que "las reservas de terrenos del Plan General de Ordenación Urbana de Las Palmas están prácticamente agotadas" (González-Ramírez 2015, 147-49).

Estas son las justificaciones que reproducirá el Plan Parcial de Ordenación del Polígono Residencial de Jinámar ${ }^{4}$, cuatro años después. La terciarización de la economía, y de forma específica el sector servicios, no es contemplado en ese Plan Parcial, pese a su pujanza: en 1964, cuatro años antes de la propuesta de expropiación, los empleos del sector servicios en Canarias eran el 11,2\% del total, y llegarían a ser el 16,6\% en 1971 - un año antes de la elaboración del Plan Parcial - y alcanzaría el 21,9\% en 1975 - cinco años antes de que el Polígono fuera definitivamente habitado -. Por el contrario, el sector industrial al que alude la propuesta de expropiación disminuyó desde el 17,2\% de 1964 al 11,2\% (1971) y a un 9,6\% (1975) (Casariego 1987, 38), lo que suponía ya en buena medida la consumación del giro de la economía canaria, y de Gran Canaria, germen de la industria turística en las Islas. El alejamiento de los vecinos de clase obrera de esa nueva dinámica económica y del empleo del conjunto de la sociedad de Gran Canaria, centrada ya en el turismo, será una de las consecuencias de su mudanza al nuevo espacio urbano.

\section{El abandono planificado y la fundación de la guetización}

Los primeros vecinos del Polígono de Jinámar procedían de Las Palmas de Gran Canaria $(56,81 \%)^{5}$, Telde $(37,37 \%) 6$, y un 5,82\% eran familias evacuadas del Sáhara ${ }^{7}$. En Las Palmas de Gran Canaria, debido a la baremación específica aplicada, quienes decían habitar en chabolas no accedieron a vivienda alguna en el primer poblamiento. En el caso de Telde, procedían de hasta 39 núcleos de población. Un 20,73\% de las familias llegaba desde el centro de la ciudad, San Gregorio. Solo 16 de las 417 familias teldenses vivían previamente en cuarterías o asimilados. Era una población que, aún sin vivienda en propiedad, procedía de la centralidad urbana de sus ciudades de origen, de barrios obreros contigüos, y de la interacción social inherente (González-Ramírez 2015, 159-75).

Las construcciones a las que llegaban eran plurifamiliares, en su mayoría de gran altura, hasta 12 plantas sobre rasante. El aislamiento, el desabastecimiento de agua potable, la inexistencia de alcantarillado y de suministro eléctrico, la carencia de infraestructuras educativas y sanitarias, y de comercio de proximidad, son algunas de las características del abandono planificado que experimentó esa misma población a su llegada, especialmente

4 Archivo Servicio de Arquitectura y Urbanismo del Ayuntamiento de Las Palmas de Gran Canaria. Expediente 62B. Carpeta 57. Madrid. Enero de 1972. "Plan Parcial de Ordenación Urbana Residencial del Polígono de Jinámar y proyecto de parcelación".

5 La Provincia. 14 de febrero de 1980, 6-34. Relación de adjudicatarios de las viviendas de Jinámar.

6 La Provincia. 16 de diciembre de 1979, 6-7-22. Adjudicación provisional de 434 viviendas del Polígono de Jinámar.

7 La Provincia. 19 de diciembre de 1979, 10. Adjudicación provisional de viviendas a evacuados del Sáhara. 
durante el primer lustro, y que suponen la fundación del proceso de guetización de ese espacio sociourbano, en un territorio especialmente hostil para su población más numerosa, la infanto-juvenil.

El desabastecimiento de agua era en 1980 un problema insular, hasta el extremo de anunciarse un plan de emergencia. En el caso del Polígono de Jinámar, el grupo de gobierno teldense alerta sobre "la falta de infraestructura higiénico-sanitaria, con montaje de depuradoras y abastecimiento de agua adecuados", y un verdadero mapa de la ausencia de servicios públicos: la evacuación de las aguas negras discurre por el cauce público y llegan al mar formando verdaderas lagunas en la playa de la Condesa, y anuncia que existen once casos de hepatitis, los locales comerciales "convertidos en focos de infección", la inexistencia de conexión entre la zona alta y baja del Polígono y la ausencia de reserva de suelo para construir centros escolares (González-Ramírez 2015, 222-55).

Figura 3. Asentamientos en el Valle de Jinámar, según información catastral.

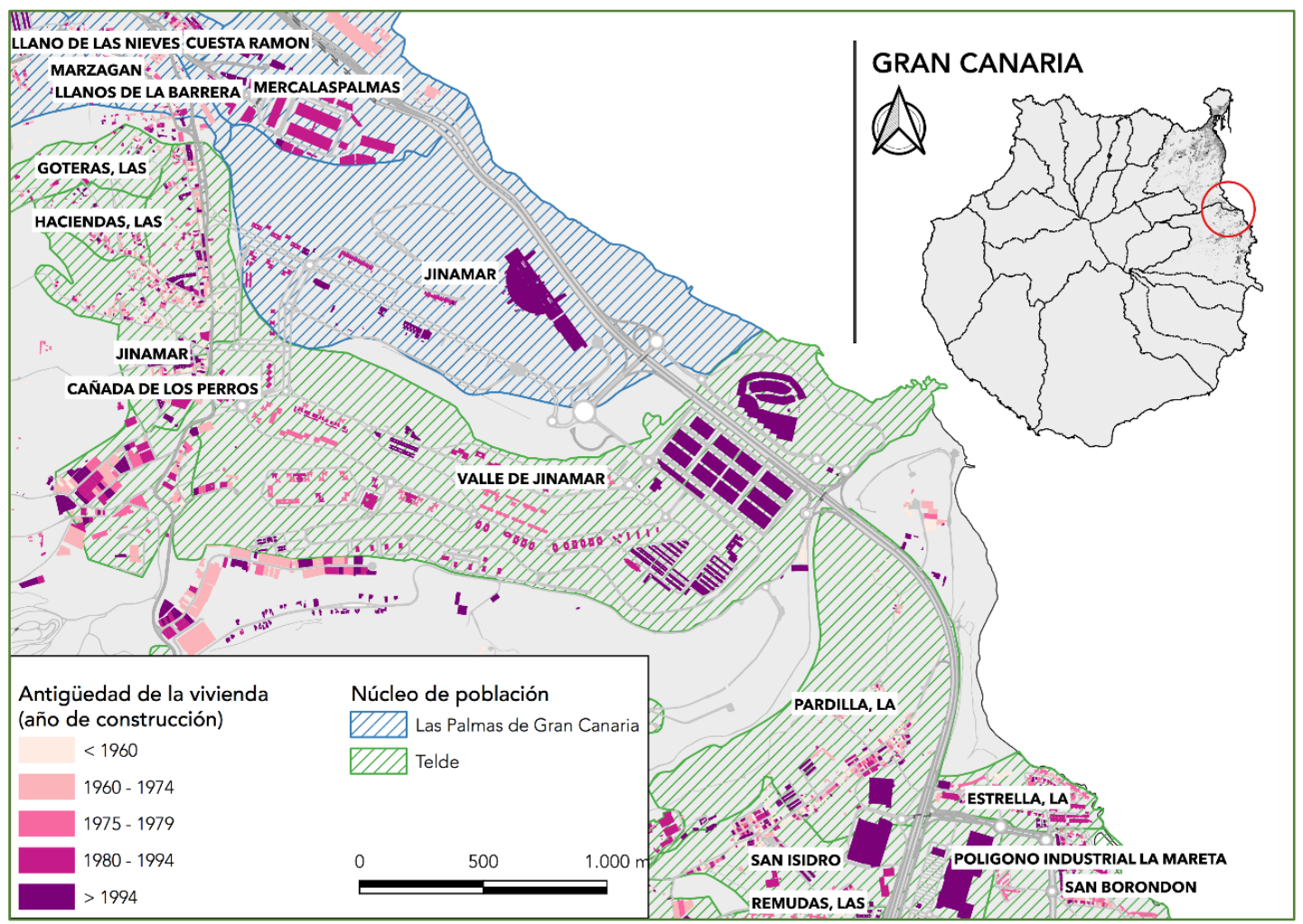

Autor: Jordi Boldú, a partir de datos de la DG del Catastro.

Los primeros niños del Polígono de Jinámar cuentan con un solo colegio de Educación Primaria, el Colegio Nacional Montiano Placeres. Las Palmas de Gran Canaria había concedido vivienda con un baremo específico, distinto al estatal, que supuso que más de 2.500 menores de edad formaran parte de la primera población del nuevo espacio urbano. Esos menores, protegidos con una nueva vivienda digna, sufrieron una debacle en su logro educativo, que cuando menos condicionaría su posterior itinerario vital y laboral: el primer curso escolar, el 80/81, el 62,96\% de los niños de 8o de EGB aprobó, pero solo dos cursos académicos después ese porcentaje cayó al 16,67\%. Solo un $8 \%$ de los alumnos que iniciaron 
la segunda etapa de EGB cuando llegó al nuevo barrio logró concluirla en el año que les correspondía. El logro educativo experimenta una debacle en cada nivel de la segunda etapa educativa: pasa del 38\% de aprobados (80/81) al 20\% (82/83) en 60 de EGB; del 40\% $(80 / 81)$ al 25\% (82/83) en 7o de EGB; y la ya señalada caída hasta el 16,67\% en 8o de EGB (González-Ramírez 2015, 387-485).

El desempleo de los padres de familia al llegar al nuevo barrio era de alrededor del 14\%, según las fichas originales de los trabajadores sociales que fiscalizaron la baremación ${ }^{8}$. En 1986, la tasa de desempleo detectada es del 54,7\%. El 91,4\% de los jóvenes de entre 16 y 19 años está en situación de desempleo. Según el primer informe autonómico sobre la situación socioeconómica de los vecinos, por cada persona que recibe algún tipo de ingresos, otras tres personas dependen de ella. Un 6,6\% de la población tenía ingresos por pensiones diversas: paro, jubilación, orfandad, invalidez, viudedad, beneficencia. Un 86\% de los parados del Polígono de Jinámar carecía de seguro de desempleo (González-Ramírez 2015, 376-78).

Los informes municipales apuntan a la misma situación socioeconómica. En 1986, un $20 \%$ de las familias del Polígono de Jinámar había solicitado ayudas sociales al Ayuntamiento de Telde. El 28,5\% de las familias no come nunca carne ni pescado, un 49,5\% come un día carne a la semana, y otros dos días pescado; un 18\% puede ingerir dos días a la semana carne, y otros dos días pescado. La apertura del Centro de Salud permitió, además de la atención sanitaria, determinar las condiciones precisas de la población. Así, se detectó a través de la consulta de pediatría cómo las medias de talla y peso de los bebés menores de seis meses, especialmente los de las fases I y II de vivienda pública "no alcanzan la media normal de estas edades, que se sitúa en torno al percentil 50 [...] en Jinámar la media de estos bebés está en el percentil 25", por lo que se toma la determinación de "repartir leche maternizada en el Polígono" (Montesdeoca 1986).

En el segundo semestre de 1986, era una “comunidad aislada social y físicamente", y se señalan las características únicas del espacio urbano como generadoras de ese aislamiento y exclusión, pues si bien se considera que "es una promoción oficial con el componente sociodemográfico habitual para este tipo de construcciones", se subraya su "característica particular, que quizás haga incrementar el desarraigo [...] por la discontinuidad espacial". El Polígono de Jinámar "produce un desarraigo globalizador grave, donde entran componentes de tipo cultural, psicológico y relacional", y donde se señala como determinante la ubicación por la distancia en las que fueron desplazados de la ciudad, "sin continuidad con el sistema urbano, con la carencia de infraestructura social que margina aún más la población”9.

Las alarmas institucionales se suceden. En abril de 1984, bajo el contundente epígrafe de 'Alarmante situación de hambre en el Polígono de Jinámar', el grupo gobernante presenta al pleno municipal de Telde una moción en la que diagnostica una situación "impensable en

8 Archivo Edei Consultores. 1979. Fichas de peticionarios de vivienda en Las Palmas de Gran Canaria. [sin catalogar]

9 Marco de Programa de Actuaciones en el Polígono de Jinámar. 1986, 30-31-53. En Montesdeoca, D (Coord.), Seminario sobre crecimiento vecinal y tratamiento de barrios. Las Palmas de Gran Canaria: Gerencia del Polígono de Jinámar. Gobierno de Canarias. 
los tiempos que corremos, con familias que pasan hambre física, siendo unas trescientas personas de las cuales la mayoría son niños". El 31\% de las solicitudes de ayudas económicas de todo el municipio, y el $17 \%$ de las peticiones de ayudas económicas no periódicas, proceden del Polígono de Jinámar. De ellas, un 75\%, de personas de la tercera edad, y el 25\%, de familias numerosas. El pleno municipal diagnostica que "se ha construido un barrio gigante limitándolo a viviendas", y exige "parar la política de viviendas de grandes edificios" (González-Ramírez 2015, 373-86).

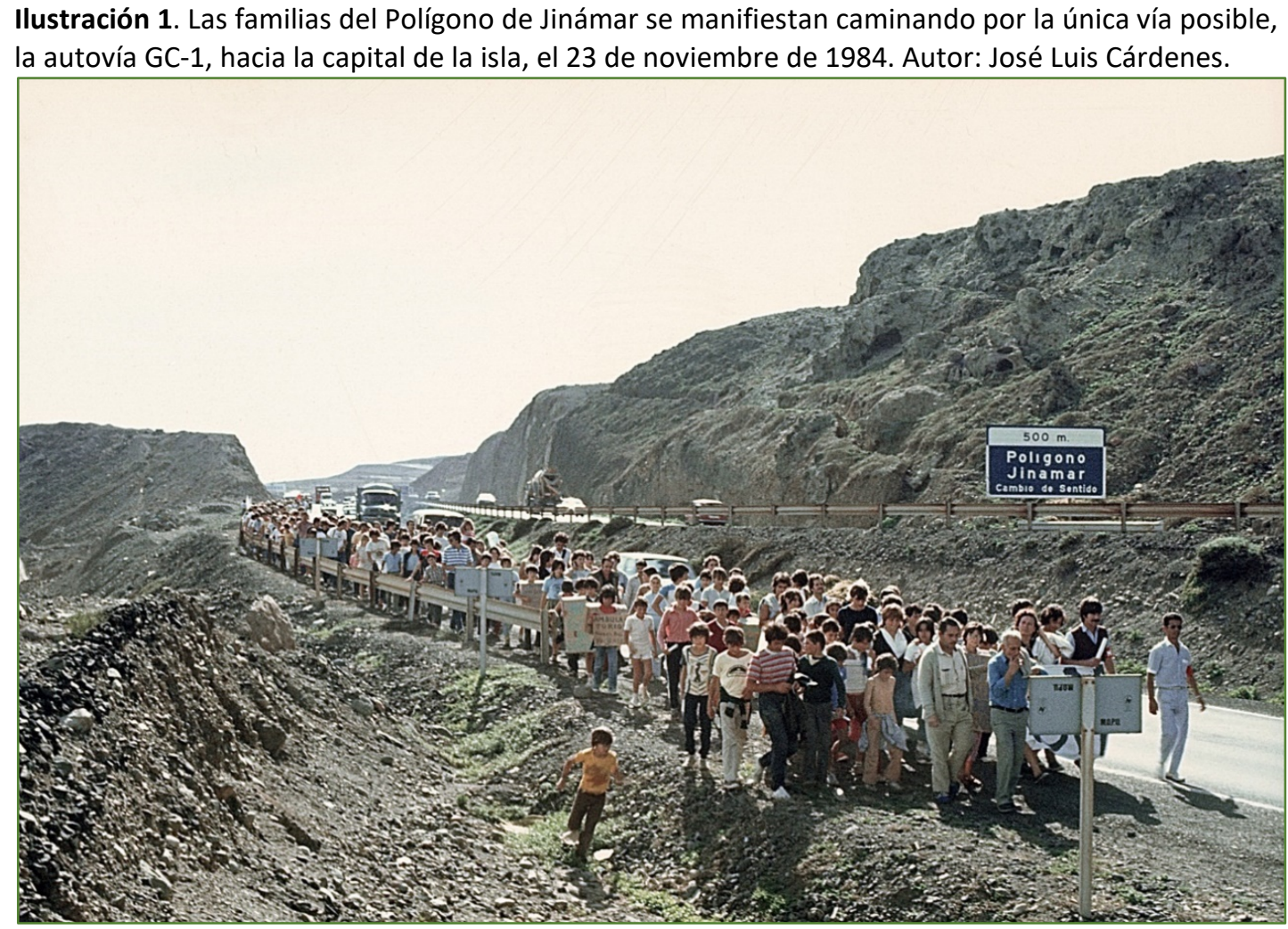

Fuente: González-Ramírez 2015.

\section{Estigmatización y apropiación vecinal}

El Polígono de Jinámar era ya una categoría de espacio urbano de exclusión, comparado con el Pozo del Tío Raimundo, referente español de la marginación urbana, por parte de especialistas del Ministerio de Sanidad y Consumo, bajo la diagnosis común de "la falta de integración social" 10 . Esa supuesta "falta de integración" parecía tener causas más tangibles. La presencia de la situación extrema de sus habitantes en la prensa era permanente, con el señalamiento del "hambre física" de las familias y la difusión de informes por parte del propio Ejecutivo canario en el que se señalaba que "21.000 personas están en una situación de

10 La Provincia. 9 de julio de 1986, 6. El doctor Yuste comparó los problemas de Jinámar con los del Pozo del Tío Raimundo. 
extrema necesidad, de carencia y deficiencia de todo tipo", y en el que se describía un paisaje sin matices de incluso "abandono, maltrato y utilización de niños"11.

Una de las iniciativas para afrontar ese estigma fue la reclamación vecinal de modificación del nombre del espacio urbano, para recuperar el original de Valle de Jinámar. "Un grupo de vecinos y asociaciones del Polígono de Jinámar ha planteado la posibilidad de cambiar esta denominación, sustituyendo el nombre actual por el de Valle de Jinámar"12, se informaba en agosto de 1985. No debía ser casualidad, sin embargo, que la primera ocasión en que esa reclamación logra difusión, fuera en el contexto de una información en la que los vecinos del Polígono de Jinámar reciben la respuesta a la demanda de empleo que, de manera masiva, se ha hecho a las empresas de la Isla para que contraten parados del Polígono: sólo 8 trabajadores de todo el barrio son contratados.

La pugna por la apropiación vecinal del espacio se produjo, principalmente, con la creación continua de organizaciones formales representativas. A la Comisión de Afectados por la Vivienda en Telde y la Coordinadora Pro Vivienda, convertida más tarde en Coordinadora Popular de la Vivienda, de carácter supramunicipal, sucedieron múltiples asociaciones vecinales específicas del barrio ${ }^{13}$. El resultado fue la conformación de un amplio Movimiento Vecinal del Valle de Jinámar. Su culmen fue la manifestación de 23 de noviembre de 1984, en que se paralizó el barrio, y familias enteras recorrieron los 15 kilómetros que las separaban de Las Palmas de Gran Canaria por la única vía posible, la autovía GC-1, hasta llegar a la sede de la Presidencia del Gobierno de Canarias. Los propios vecinos hacían manifiesto ese proceso de apropiación al reclamar en un documento entregado al entonces presidente, Jerónimo Saavedra Acevedo, la necesidad de "recabar atención sobre los problemas sanitarios, educativos y urbanísticos que asuelan nuestro barrio, en la esperanza de que a partir de esta jornada los habitantes del polígono comenzarán a adquirir conciencia de que tendrán que ser protagonistas de su propio futuro" (González-Ramírez 2015, 301).

\section{Conclusiones}

El análisis de la producción del Polígono de Jinámar y de los procesos sociales derivados permiten su consideración como espacio sociourbano de exclusión en un ámbito atlántico insular, con características que lo vinculan con espacios globales de igual consideración - el gueto norteamericano, la periferia urbana francesa -, y características específicas que lo convierten en un fenómeno excepcional en el desarrollo urbano y social del Estado español y del Archipiélago canario.

Esa producción como espacio sociourbano excepcional deslizó al grupo humano segregado - familias de clase obrera - desde una situación de carencia habitacional a una situación de polipatología carencial, de acumulación de marginación y, finalmente, de

11 La Provincia. 3 de agosto de 1985, 7. Jinámar: 21.00 personas en situación de extrema necesidad.

12 La Provincia. 3 de agosto de 1985, 9. La empresa privada ofreció 8 puestos de trabajo a los parados de Jinámar.

13 AAVV El Corredera, 30 de Diciembre, La Noria, Armiche, Jinámar Nuevo Futuro, Xinaguada, Atacaicate, Tenesor, El Palmeral, Asociación Juvenil Ansite, Asociación Jóvenes de Jinámar, Asociación Cultural Tercera Fase, APA Montiano Placeres, APA Rafael Alberti. 
exclusión, que supuso la producción consiguiente - en cuanto que segregación planificada desde la iniciativa pública estatal - de una nueva categoría de desigualdad de origen específicamente urbano.

La proposición como espacio sociourbano de exclusión se circunscribe al periodo acotado de investigación (1967-1987), y de forma precisa desde su primer poblamiento, en febrero de 1980, en lo que consideramos periodo fundacional e incubación de su proceso de guetización.

Entre esas características específicas, se encuentra el periodo de su producción, entre la dictadura y la democracia, como iniciativa estatal derivada de los intereses vinculados de las relaciones de la élite propietaria en el ámbito insular con las instituciones políticas estatales. La adquisición de los terrenos al Condado de la Vega Grande se realizó pese al informe inicial de que esa compra era innecesaria. La excepcionalidad de su producción se corresponde con su iniciación por parte de un régimen dictatorial, y su ejecución posterior en los primeros años del sistema democrático.

De otro lado, su aislamiento, sin contigüidad con la ciudad, propicia que sus vecinos sean los primeros expulsados aislados en los procesos de conformación de la capital grancanaria. La compra excepcional de su suelo derivó en la producción de un espacio sociourbano que fractura la tradicional estrategia de búsqueda de soluciones habitacionales en la isla: tanto la iniciativa estatal como las estrategias familiares de búsqueda de vivienda se hacían, hasta entonces, en contigüidad con la ciudad.

La segregación de sus vecinos se sustenta en la clase social: familias de clase obrera, siendo su población infanto-juvenil la más numerosa. Condicionados, además, por su división administrativa, entre Las Palmas de Gran Canaria y Telde, y sin recursos públicos esenciales: un único colegio público, sin agua potable, presencia de aguas fecales, ausencia de luz eléctrica, dificultades de transporte público, inexistencia de servicios sanitarios, entre otras carencias.

Este embolsamiento de las clases bajas con carencia habitacional de Gran Canaria se produce de forma paralela a la producción de espacios para el turismo, en lo que entendemos un fenómeno de explotación de recursos como mecanismo causal de la desigualdad. En un contexto de emergencia de la actividad turística, la segregación residencial de la clase obrera se relaciona con su desvinculación del espacio urbano precedente y del empleo. La adquisición estatal de los terrenos se encuentra igualmente relacionada con la necesidad de financiación para el desarrollo de la actividad turística: se compra el suelo sin necesidad previa, mientras la titularidad del mismo busca financiación para el desarrollo de sus proyectos turísticos privados. Los intereses de una élite insular de la propiedad del suelo determinaron una solución traumática a la carencia habitacional de la ciudad, propiciando la segregación y la posterior exclusión de esas familias de clase obrera.

La fractura en la interacción social, derivada del aislamiento, la desposesión del derecho a la ciudad y su relegación respecto de la centralidad sociourbana, económica y política de los vecinos del Polígono de Jinámar, se encuentra en el origen de la gestación de esa nueva desigualdad, según el modelo relacional teórico desde el que hemos abordado nuestro análisis. Esa quiebra en la interacción social provocada por el aislamiento, y el 
desproveimiento de oportunidades como mecanismo causal - su expresión más clara es la desigualdad respecto de los recursos educativos, y también los sanitarios -, así como la carencia de otros servicios básicos, se relaciona y está en el origen, entendemos, de la disminución de todos los parámetros de bienestar - educativos, sanitarios y de empleo documentados.

Esas condiciones de vida producidas en el Polígono de Jinámar provocaron, entendemos, un deslizamiento desde la carencia de vivienda a una acumulación de marginalidad, a la producción de una nueva categoría de desigualdad, inexistente en otros ámbitos de la isla ni del Archipiélago. En sólo cinco años - de 1980 a 1985 - los valores relativos a desempleo, tasa de natalidad, malnutrición, e ingreso económico suponen un tránsito evidente desde la génesis de la exclusión hasta su consumación. La exclusión no es sólo material, sino igualmente simbólica, como ponen de manifiesto sus vecinos en relación a la estigmatización percibida y pugnada mediante la reclamación de un cambio de denominación para el barrio: de Polígono de Jinámar a Valle de Jinámar.

Su consideración como espacio de exclusión, con las características de los espacios de exclusión globales de referencia, se corresponde con el cumplimiento estricto de los elementos que configuran ese espacio urbano estadounidense como espacio excluyente, destinatario de una violencia estructural masiva, caracterizada por el desempleo igualmente masivo, crónico y persistente - desproletarización -, la relegación de sus habitantes a espacios donde disminuyen los recursos públicos, y la estigmatización espacial y social. Esos tres elementos se encuentran presentes en el Polígono de Jinámar en el periodo investigado.

La desposesión de sus derechos a la relación con la ciudad, y la agresiva producción del espacio físico y relacional hostil, fue afrontada por sus vecinos con un dinámico proceso de apropiación y conformación de un espacio social propio, mediante la constitución de múltiples asociaciones y colectivos que derivaron en el Movimiento Vecinal del Valle de Jinámar. La conciencia de esa apropiación es manifiesta en el mensaje común que trasladan a las instituciones, en la multitudinaria manifestación del 23 de noviembre de 1984, en la que caminan hasta la ciudad y reclaman ser "protagonistas de su propio futuro".

Por último, consideramos el Polígono de Jinámar como expresión de la paradoja advertida por Harvey, en cuanto que medidas de aparente redistribución ocultan mecanismos que propician una mayor desigualdad. En el caso del Polígono de Jinámar, la evitación de una carencia, la falta de vivienda, condujo a un proceso de mayor desigualdad y a la generación de nuevas carencias, hasta el extremo de configurar esa categoría de desigualdad específica para los habitantes del Polígono de Jinámar, debido a su segregación, aislamiento y a la fractura de la interacción social, para su exclusión final. Igualmente, supone un ejemplo simbólico de las amenazas de los relatos y las propuestas utópicas. El caso de los primeros niños del Polígono de Jinámar es paradigmático: su mudanza a una nueva vivienda lo fue a un logro e itinerarios educativos de exclusión que hubiera sido distinto en otros contextos sociourbanos. El sector de población más vulnerable, al que se intentó ofrecer mayor protección con una nueva vivienda, resultó ser el más perjudicado en su trayectoria vital, al carecer de equidad en sus oportunidades educativas. 


\section{Bibliografía}

Auyero, Javier. 2010. Claves para pensar la marginación. En Parias urbanos. Marginalidad en la ciudad a comienzos del milenio, de Löic Wacquant, 9-31. Buenos Aires: Manantial.

Bescós Olaizola, Alfredo. 1984. Procesos de crecimiento y transformación en el área urbana de Las Palmas, durante el periodo 1950-1980. (Tesis Doctoral). Madrid: Universidad Autónoma de Madrid.

Bettin, Gianfranco. 1982. Los sociólogos de la ciudad. Barcelona: Gustavo Gili.

Burriel de Orueta, Eugenio L. 1982. Canarias: Población y agricultura en una sociedad dependiente. Barcelona: Oikos-tau.

Casariego Ramírez, Joaquín. 1987. Las Palmas: Dependencia, marginalidad y autoconstrucción. Las Palmas de Gran Canaria: Instituto de Estudios de Administración Local.

González-Ramírez, Federico E. 2015. Polígono de Jinámar. La isla interior. La producción de espacios sociourbanos y habitus educativos de exclusión (1967-1987). Tesis doctoral. Universidad de Las Palmas de Gran Canaria.

González-Ramírez, Federico E. 2017. Espacios urbanos de exclusión en las ciudades canarias. XXII Coloquio de Historia Canario-Americana (2016), XXII-044, 1-9

Hall, Peter. [1988] 1996. Ciudades del mañana. Historia del urbanismo en el siglo XX. Barcelona: Ediciones del Serbal.

Harvey, David. [1973] 2007. Urbanismo y desigualdad social. Madrid: Siglo XXI de España Editores.

Hernández Luis, J. Á. (1997-1998). El impacto de las obras públicas con fines turísticos: El caso de las Islas Canarias. Vegueta, 3, 279-289.

Lefebvre, Henri. [1968] 1975. El derecho a la ciudad. Barcelona: Ediciones Península.

Lefebvre, Henri. [1974] 2013. La producción del espacio. Madrid: Capitán Swing.

Mingione, Enzo. 1996. Urban poverty and the Underclass: A reader. Cambridge: Mass, Blackwell.

Montesdeoca, Domingo. (Coord.). 1986. Seminario sobre crecimiento vecinal y tratamiento de barrios. Las Palmas de Gran Canaria: Gobierno de Canarias.

Nadal Perdomo, Ignacio. 1983. "El territorio meridional de San Bartolomé de Tirajana. Un espacio transformado por el turismo". En El Sur de Gran Canaria: Entre el turismo y la marginación, de Ignacio Nadal Perdomo y Carlos Guitián Ayneto, 21-122. Madrid: CIES.

Parreño Castellano, Juan Manuel, y Moreno Medina, Claudio. 2006. La creación de asentamientos públicos segregados en los setenta. El caso de Jinámar (Islas Canarias, España). Ería, 70, 175-190.

Tilly, Charles. [1998] 2000. La desigualdad persistente. Buenos Aires: Manantial.

Wacquant, Löic. 2007. Los condenados de la ciudad. Gueto, periferia y Estado. Buenos Aires: Siglo XXI Editores.

Wacquant, Löic. 2010a. Las dos caras de un gueto. Ensayos sobre maginalización y penalización. Buenos Aires: Siglo XXI Editores. 
Wacquant, Löic. 2010b. Parias urbanos. Marginalidad en la ciudad a comienzos del milenio. Buenos Aires: Manantial.

(C) Copyright Federico Gonzalez Ramirez, 2021

(C) Copyright: Scripta Nova, 2021.

Ficha bibliográfica:

GONZÁLEZ-RAMIREZ, Federico E. Sociogénesis del polígono de Jinámar (1967-1987). La producción paralela de espacios de exclusión y espacios turísticos en un contexto atlántico insular (Gran Canaria). Scripta Nova. Revista Electrónica de Geografía y Ciencias Sociales. Barcelona: Universitat de Barcelona, vol. 25, Núm. 1 (2021), p. 131153 [ISSN: 1138-9788]

DOI: $10.1344 /$ sn2021.25.32444 